\title{
Melanosis coli in patients with colon cancer
}

\author{
Dorota Biernacka-Wawrzonek ${ }^{1}$, Michał Stępka², Alicja Tomaszewska ${ }^{1}$, Agnieszka Ehrmann-Jóśko ${ }^{3}$, \\ Natalia Chojnowska ${ }^{3}$, Magdalena Zemlak ${ }^{3}$, Jacek Muszyński ${ }^{3}$
}

${ }^{1}$ Department of Pathology, Medical University of Warsaw, Warsaw, Poland

${ }^{2}$ Department of Internal Medicine, Railway Hospital, Pruszkow, Poland

${ }^{3}$ Department of Gastroenterology and Metabolic Diseases, Medical University of Warsaw, Warsaw, Poland

Gastroenterology Rev 2017; 12 (1): 22-27

DOI: $10.5114 / p g .2016 .64844$

Key words: colon cancer, melanosis, anthraquinones, laxatives.

Address for correspondence: Magdalena Zemlak, Department of Gastroenterology and Metabolic Diseases, Medical University of Warsaw, 1a Banacha St, 02-097 Warsaw, Poland, phone: +48 2259929 35, e-mail: mzemlak@tlen.pl

\begin{abstract}
Introduction: Melanosis coli is a benign lesion affecting the mucosa of the large intestine. There is a relationship between the presence of melanosis and anthraquinone laxative use. Melanosis coli is also observed in patients with colon cancer, but there is doubt whether these two conditions are related.

Aim: To analyze the correlation between melanosis and colon cancer.

Material and methods: We analyzed retrospectively 436 patients undergoing colon cancer surgery. There were 246 women and 190 men. Patients were divided into three age groups: under 50 years, between 51 and 65 years, and over 66 years. We analyzed sections of the cancer and intestinal mucosa from the tumor's proximal $(2-5 \mathrm{~cm})$ and distal $(8-10 \mathrm{~cm})$ zone.

Results: Melanosis coli was present in 52 patients, which represents $11.9 \%$ of patients with colon cancer. More often it was present in women. The most common location of melanosis and colon cancer was the terminal part of the large intestine. In patients below 50 years of age in both sexes melanosis coli did not occur. In men, melanosis was more common in the age group over 66 years. Intensity of pigmentation was higher in the tumor's distal zone.

Conclusions: The incidence of melanosis coli increases with age, similar to that of colon cancer. Melanosis was not present inside tumors, in almost half of the cases it was not present in the proximal zone, and the degree of pigmentation increased in distal zone. The cause-effect relationship between melanosis coli and colon cancer remains uncertain.
\end{abstract}

\section{Introduction}

Colorectal cancer is one of the main concerns of modern medicine. It is the most common type of cancer in Europe and constitutes $13.3 \%$ of all malignant neoplasms. The incidence of colorectal cancer has surpassed lung cancer (13.1\%) and breast cancer (12.2\%). Colorectal cancer is the second leading cause of death from cancer after lung cancer (12.3 vs. $19.9 \%$ ) respectively [1].

In Poland in 2010 colon cancer incidence in men was third (12.4\%) after lung (21.2\%) and prostate cancer $(13.2 \%)$. In women it was second $(10.1 \%)$ to breast cancer $(22.4 \%)$. For the same period it was the second most deadly type of cancer in men $(11.5 \%$ of all cancer-related deaths in men; lung cancer - 31.3\%) and third in women (11.5\%; lung cancer - $15.1 \%$, breast cancer $12.8 \%$ ) [2]. The pathogenesis of colon cancer is not fully understood, but environment, inflammation and genetic factors play important roles [3-6].
A body of research is looking at the relation between the use of anthraquinone laxatives, melanosis coli and colon cancer [6-16]. In developed countries anthraquinone laxatives are used by $20 \%$ of the population [14]. Their long-term use leads to melanosis coli, as was shown in many studies [7, 16-26]. Melanosis coli is brown discoloration of the colonic mucosa resulting from pigment deposition, and it is seen during endoscopy. Darkening of the mucosa may also be a result of hyperemia and not necessarily melanosis - and it is usually more intense $[8,12,22,27]$. At times, the pigmentation is evident only in microscopy [14, 22]. Endoscopy has sensitivity of $72 \%$ and specificity of $52 \%$ when compared to the reference method, which is histopathology $[25,27]$. The microscopic view reveals the presence of pigment in macrophages of the lamina propria and submucosa, and sometimes pigment is extracellular, probably a result of macrophage breakdown 
$[8,11,18-20,28,29]$. In rare cases pigment has been found in regional lymph nodes [11, 23, 29]. No pigment has ever been found in intestinal epithelial or plasmatic cells or lamina propria lymphocytes [30, 31].

Electron microscopy studies led to the conclusion that the melanosis results from phagocytosis of apoptotic enterocytes. Apoptotic bodies are phagocytosed and degraded to lipofuscin by macrophages migrating into the lamina propria [19, 32-34].

\section{Aim}

The aim of this study is to analyze the incidence and severity of melanosis coli in patients with colon cancer. We also want to determine the relation between the degree of melanosis and the incidence of colon cancer. Our final aim is to determine the relation between the degree of melanosis and distance from the cancer.

\section{Material and methods}

We analyzed retrospectively 436 patients undergoing colon cancer surgery between 1985 and 1996. There were 246 (56.4\%) women and 190 (43.6\%) men. Whole resected fragments of colon were analyzed. The collected data included sex, age, location of cancer, degree of pigmentation and distance from lesion. Patients were divided into three age groups: 1 . under 50 years, 2 . between 51 and 65 years, 3. over 66 years.

Four main locations of cancer were established: 1. cecum, ascending colon, right colonic (hepatic) flexure, 2. transverse colon, left colonic (splenic) flexure, 3. descending colon, sigmoid (these two were put in one group due to the small number of cancers in the descending colon), 4 . rectum.

The specimens were fixed in $10 \%$ buffered formalin, embedded in paraffin, sectioned at 5 microns and stained with hematoxylin and eosin. We analyzed sections of the cancer and intestinal mucosa from the tumor's proximal $(2-5 \mathrm{~cm})$ and distal $(8-10 \mathrm{~cm})$ zone. The World Health Organization histological classification system was used in assessment of colon cancer [35]. The degree of melanosis pigmentation was assessed: 1 - within the tumor, 2 - in the tumor's proximal zone, 3 - in the tumor's distal zone.

The following grading was used to assess pigmentation: 0 - no changes, I - low grade - isolated macrophages containing pigment present in lamina propria, II - medium grade - between I and III - pigment containing macrophages in lamina propria, III - high grade - cluster of pigment containing macrophages in lamina propria.

\section{Statistical analysis}

In the statistical analysis the results (frequency and standard deviation) were estimated on the basis of a binomial distribution. For all data, comparison was performed with Student's $t$-test. Statistically significant data were considered as $p$-values $<0.05[36,37]$.

\section{Results}

Melanosis coli was present in 52 patients, which represents $11.9 \%$ of patients with colon cancer. Melanosis was present in 32 women (13\% of women included in the study and $7.3 \%$ of all studied patients) and in 20 men $(10.5 \%$ of men included in the study and $4.6 \%$ of all studied patients) (Figure 1).

\section{Colon cancer in patients with melanosis coli occurring in older patients}

Mean age of patients with colon cancer and melanosis was $69.2 \pm 10.9$ years, and mean age of patients with colon cancer but without melanosis was 64.8 \pm 11.9 years. The difference was statistically significant $(p<0.001)$. Mean age of women with colon cancer and melanosis was $68.09 \pm 10.98$ years, and in men it was $70.9 \pm 10.87$ years. This difference was not statistically significant.

\section{Melanosis coli and patients' sex and age group}

In patients below 50 years of age in both sexes melanosis coli did not occur. The prevalence of melanosis in women aged $51-65$ years and 66 years and over as a percentage was similar.

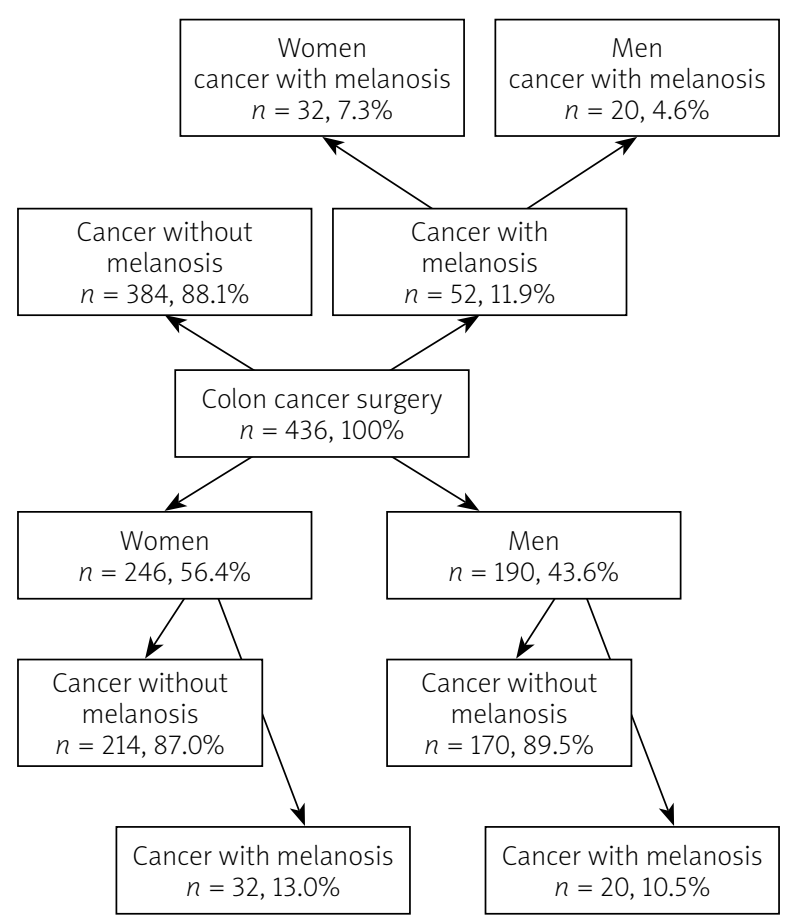

Figure 1. Pattern of material analysis 


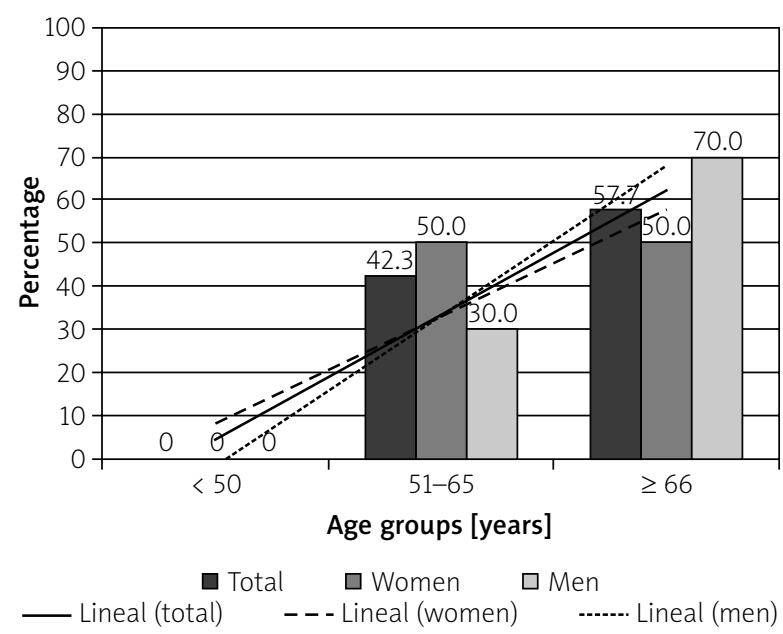

Figure 2. Melanosis coli and colon cancer in different age groups

In men melanosis was more common in the age group over 66 years (Figure 2).

\section{Location of melanosis coli}

The most common location of melanosis and colon cancer was its terminal part (sigmoid and rectum), and - in descending order - the transverse colon and cecum. In cases where there was no melanosis the location of tumors was similar.

\section{Intensity of melanosis in tumor's proximal and distal zones}

Of the 52 studied patients, the cancer accompanied by melanosis in 45 cases was moderately differentiated adenocarcinoma (G2), in 4 cases the tumor was mucinous carcinoma, and in 3 cases the tumor showed neuroendocrine differentiation. No case was found of melanosis within the tumor. No melanosis was noted in the tumor's proximal zone in $24(46.2 \%)$ patients. The distal zone was melanosis-free in $3(5.8 \%)$ patients. This difference was statistically significant $(p<0.001)$ (Figure 3).

In the distal zone the intensity of pigmentation was higher than in the proximal zone. The difference was significant for all grades of pigmentation (low grade: $p<0.001$; medium grade: $p<0.05$; high grade: $p<0.03$ ) (Figure 3).

Low grade melanosis in the distal tumor region in colon mucous membrane expressed as a percentage of visual fields was statistically significantly lower in women than in men $(p<0.001)$.

No significant differences were noted in medium and high grade melanosis (Figure 4).

\section{Discussion}

Melanosis coli was first described by Andral and Cruveilhier in 1830 as black discoloration of the colonic mucosa in the autopsy of a patient with chronic diarrhea. Virchow used the term melanosis for this finding in 1858 [38].

Debray et al. [8] distinguished three forms of it based on etiopathogenesis: 1 . idiopathic, diffuse, occurring throughout the intestine - rarely observed, 2. melanosis caused by anthraquinone laxative overuse, 3. melanosis accompanying colon cancer.

Melanosis near cancer may be related to anthraquinone laxative overuse [8, 15, 26, 29]. Reported incidence of melanosis coli ranges from 1 to $59.5 \%$ [7, 11, 15-17, 22, 28, 39]. Koskela et al. [28] found melanosis coli in $59.5 \%$ of consecutive autopsies. However, in a multicenter autopsy study done in Scotland, Norway and Finland melanosis was found in $34 \%$ of cases [28]. Siegers et al. [16] in a retrospective study of 3049 endoscopies found melanosis coli only in $3.13 \%$ of lesion-free patients, in $8.64 \%$ of patients with adenoma and in $3.29 \%$ of patients with colon cancer. In a prospective analysis of 1095 endoscopies by the same authors the incidence of melanosis coli was higher; it was found in $6.9 \%$ of lesion-free patients, in $9.8 \%$ of patients with adenoma and in $18.6 \%$ of patients with colon cancer. The difference between retrospective and prospective studies is explained by incomplete documentation of the retrospective study. Prospective studies showed a potential correlation between melanosis and cancer which was thought to be caused by coexisting constipation treated with anthraquinone laxatives [16].

Morgenstern et al. [11] in 511 colon cancer patients undergoing surgery found melanosis coli in only 30 (5.9\%) cases.

In our retrospective analysis of 436 cases of colon cancer, melanosis coli was present in 52 (11.9\%) patients, which was almost two times more than in a similar group from Morgenstern's study [11] and a retrospective endoscopy study by Siegers et al. [16], and much less than in Koskela's autopsy study [28] and a prospective analysis by Siegers et al. [16].

The incidence of melanosis increased with patients' age and was related to constipation and anthraquinone laxative use. The same conclusions were presented by Siegers and Koskela [16, 28].

In our analysis, melanosis was present only in patients older than 50 years.

Price et al. [40] described a case of a 4-year-old girl with melanosis coli related to constipation treated with anthraquinone laxatives. 

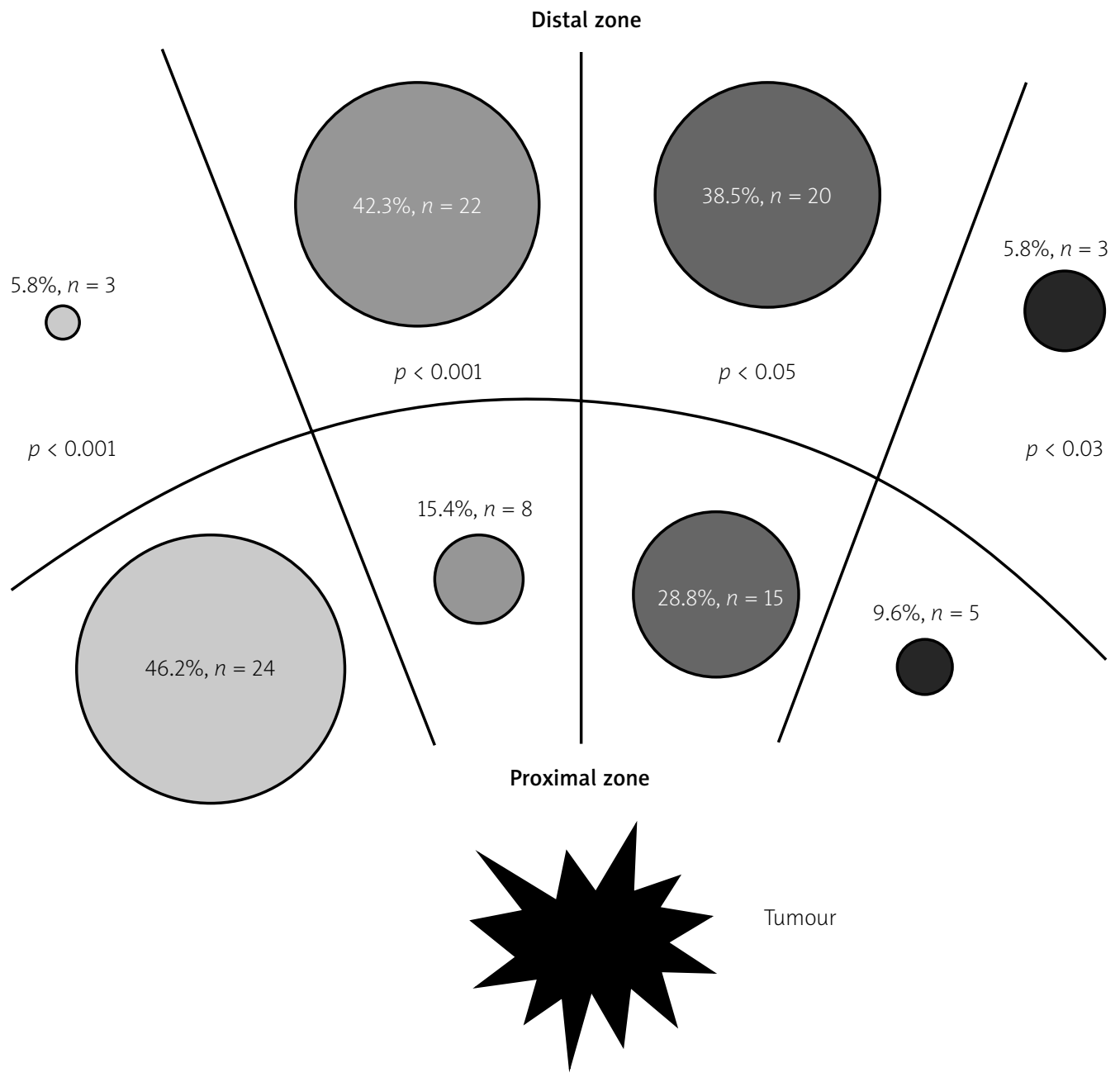
No changes
Medium grade
Low grade
High grade

Figure 3. Incidence of colon cancer in patients with melanosis in relation to melanosis intensity in proximal and distal zones $(n=52,100 \%)$

Siegers' analysis [16], as well as the studies from Mayo Clinic [28], showed higher melanosis incidence in women. It is most probably caused by constipation occurring more commonly in women and the consequent use of anthraquinone laxatives. The work of Swedish researchers [16] as well as studies by Henschen and Bergstrand [41] and Koskela [28] - similarly to our results - did not show significant differences between the incidence of melanosis in men and women.

We did not find melanosis within the tumor or in the tumor's proximal zone. Similar results were presented by Morgenstern et al. [11], Nusko [15], Puppa and Colombari [29] and Regitnig and Denk [32]. In benign lesions (adenomas) no melanosis was found according to other studies [11, 13, 15, 26, 29, 32, 41], although Coyne described melanosis in adenomatous and hyperplastic polyps [42, 43]. In studies using anti-CC3 antibodies

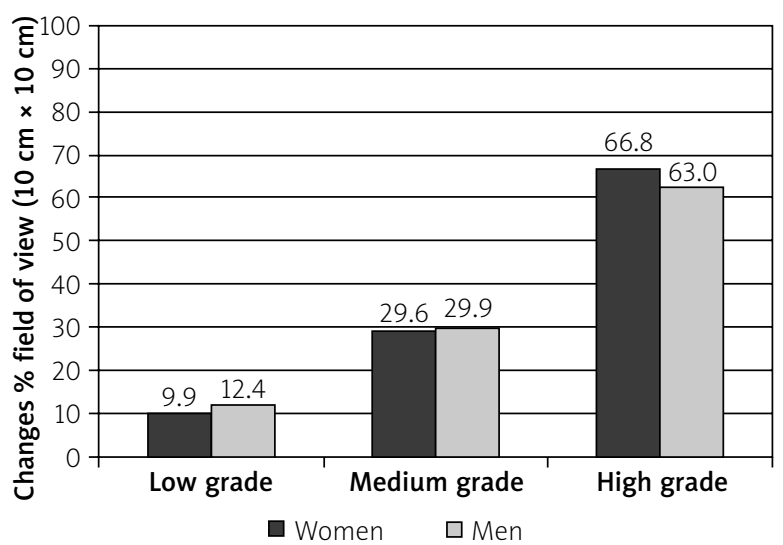

Figure 4. Degree of colonic mucosal pigmentation in distal zone in men and in women. Comparison of changes expressed in percentage of visual field - $t$-test 
(cleaved caspase-3) that indicate apoptosis, Wang et al. [41] found that apoptosis increases in adenomas' epithelium and decreases in adenomas' lamina propria. This would confirm the hypothesis of decreased ingestion of apoptotic material by macrophages present in adenoma's lamina propria or of losing apoptotic material into the lumen of the intestine. To date there have been no studies using such a diagnostic method to evaluate the occurrence and intensity of melanosis in mucosa in various tumor regions.

In our study there were more melanotic lesions in the distal zone in all three pigmentation groups, with statistical significance: low grade $p<0.001$, medium grade $p<0.05$ and high grade $p<0.03$. When the intensity of pigmentation was compared between men and women, we observed melanosis more often in men and only in low grade pigmentation in the distal zone $(p<0.01)$.

Nusko et al. [15] described the pigmentation as low or high grade. In their study they found that low grade melanosis was statistically significantly more common in patients with colon cancer. They did not find a relationship between macroscopic melanosis (seen at endoscopy) and high grade pigmentation and colon cancer. Morgenstern et al. [11] explains the absence of pigment in the tumor by factors produced by its epithelium which inhibit pigmentation and macrophage activity. The relationship between melanosis coli and anthraquinone laxative use and colon cancer is discussed in a number of papers [14, 16, 17, 21, 22, 24, $25,27,29,44]$. Although Siegers et al. [16] suggested a positive correlation, most researchers do not confirm it $[10,13,15,29,39]$. This study with an insignificant degree of coexistence of colon cancer and melanosis coli seems to disprove such a relationship. What is more, patients with colon cancer and melanosis were older than patients without melanosis, so it does not influence the speed of the process. This analysis was not able to establish a relationship between melanosis and colon cancer, as only in $11.9 \%$ of patients did these two conditions coexist. Lower incidence of melanosis in the tumors' proximal zone seems to confirm Morgenstern's [11] suggestion that factors inhibiting macrophages may be produced. Location of the cancer had no influence on the relationship between melanosis and colon cancer as cancer had a similar distribution in the colon irrespectively of being accompanied by melanosis.

Regitnig and Denk [32] and Van Weyenberg et al. [26] observed that empty (not containing pigment) macrophages were present near the crypts and macrophages containing pigment were found mostly in the central part of lamina propria between crypts, and their number increased approaching the muscular layer. This had the following interpretation:

1. macrophages move through the blood vessel wall and migrate into the lamina propria of the mucosa,

2. macrophages move toward the crypts, ingesting apoptotic material,

3. loaded with pigment, macrophages migrate into the lamina propria between crypts, then into lymphatic vessels and nodes.

According to this hypothesis, the phagocytosed apoptotic fragments appear during their travel toward the crypt, and degradation and pigment formation begins in the superficial area between crypts and increases in intensity as macrophages move towards the lamina propria and muscle layer. In colon cancer this pathway seems to be disturbed [32].

\section{Conclusions}

The incidence of melanosis coli increases with age, similarly to colon cancer. Melanosis was not present inside tumors, in almost half of the cases it was not present in the proximal zone, and the degree of pigmentation increased in the distal zone. The cause-effect relationship between melanosis coli and colon cancer remains uncertain.

\section{Conflict of interest}

The authors declare no conflict of interest.

\section{References}

1. Ferlay J, Parkin DM, Steliarova-Foucher E. Estimates of cancer incidence and mortality in Europe in 2008. Eur J Cancer 2010; 46: 765-81.

2. Wojciechowska U, Didkowska J. Nowotwory w Polsce w 2012 roku. Nowotwory J Oncol 2013; 63: 197-216.

3. Andrzejak A, Leszczyszyn J, Jurga M. The role of same metal elements and free components in the carcinogenesis. Gastroenterol Pol 1996; 3: 79-84.

4. Lynch $\mathrm{HT}$, de la Chapelle A. Hereditary colorectal cancer. N Engl J Med 2003; 348: 919-32.

5. Potemski P. Epidemiologia, badania przesiewowe i klasyfikacja zaawansowania klinicznego raka jelita grubego. Epidemiology, screening and staging of colorectal cancer. Onkol Prak Klin 2010; 6: 283-9.

6. Sandler RS, Lyles CM, McAuliffe C, et al. Cigarette smoking, alcohol, and the risk of colorectal adenomas. Gastroenterology 1993; 104: 1445-51.

7. Biernacka D. Melanosis coli. Pol Tyg Lek 1982; 37: 207-9.

8. Debray C, Paolaggi JA, Leymarios J, et al. La Melanose Recto-Colique. Sem Hop Paris 1967; 29: 1898-906.

9. Kune GA, Kune S, Field B, et al. The role of chronic constipation, diarrhea, and laxative use in the etiology of large-bowel cancer. Data from the Melbourne Colorectal Cancer Study. Dis Colon Rectum 1988; 31: 507-12. 
10. Kune GA. Laxative use not a risk for colorectal cancer: data from the Melbourne Colorectal Cancer Study. Z Gastroenterol 1993; 31: 140-3.

11. Morgenstern L, Shemen L, Allen W, et al. Melanosis coli. Changes in appearance when associated with colonic neoplasia. Arch Surg 1983; 118: 62-4.

12. Mui ACW. Melanosis coli. HK Pract 2003; 25: 124-6.

13. Nusko G, Schneider B, Ernst H, et al. Melanosis coli - a harmless pigmentation or a precancerous condition? Z Gastroenterol 1997; 35: 313-8.

14. Nusko G, Schneider B, Müller G, et al. Retrospective study on laxative use and melanosis coli as risk factors for colorectal neoplasma. Pharmacology 1993; 47: 234-41.

15. Nusko G, Schneider B, Schneider I, et al. Anthranoid laxative use is not a risk factor for colorectal neoplasia: results of a prospective case control study. Gut 2000; 46: 651-5.

16. Siegers CP, von Hertzberg-Lottin E, Otte $M$, et al. Anthranoid laxative abuse: a risk for colorectal cancer? Gut 1993; 34: 1099-101.

17. Badiali D, Marcheggiano A, Pallone F, et al. Melanosis of the rectum in patients with chronic constipation. Dis Colon Rectum 1985; 28: 241-5.

18. Balázs M. Melanosis coli. Ultrastructural study of 45 patients. Dis Colon Rectum 1986; 29: 839-44.

19. Benavides SH, Morgante PE, Monserrat AJ, et al. The pigment of melanosis coli: a lecithin histochemical study. Gastrointest Endosc 1997; 46: 131-8.

20. Ghadially FN, Walley VM. Melanoses of the gastrointestinal tract. Histopathology 1994; 25: 197-207.

21. Karaman K, Pala EE, Cumurcu S, et al. Melanosis coli in different clinical presentations: report of two cases. Eur J Surg Sci 2012; 3: 92-5.

22. Kew ST. Melanosis coli. leJSME 2012; 6 (Suppl 1): 553-60.

23. Malik AH, Andrabi SI, Niayesh M. Pseudo-obstruction with pitch black colon: a very rare presentation of melanosis coli. Ulster Med J 2008; 77: 54-5.

24. Stępka M, Biernacka D, Górnicka B, et al. Is sigmorectal melanosis associated with neoplasia? Gastroenterol Pol 2006; 13 : 85-8.

25. Stępka M, Biernacka D, Górnicka B, et al. Melanoza jelita grubego - cechy charakterystyczne. Videochirurgia 2003; 8: 32-5.

26. Van Weyenberg SJ, Hoentjen F, Thunnissen F, et al. Pseudomelanosis coli and adenomatous polyps. J Gastrointest Liver Dis 2011; 20: 233.

27. Stępka M. Melanoza jelita grubego. Terapia 2003; 6: 50-2.

28. Koskela E, Kulju T, Collan Y. Melanosis coli. Prevalence, distribution, and histologic features in 200 consecutive autopsies at Kuopio University Central Hospital. Dis Colon Rectum 1989; 32: 235-9.

29. Puppa G, Colombari R. Brown colon (melanosis coli) harbouring pale tumors (adenocarcinoma and an adenomatous polyp). J Gastrointest Liver Dis 2009; 18: 509-11.

30. Ghadially FN, Parry EW. An electron-microscope and histochemical study of melanosis coli. J Pathol Bacteriol 1966; 92: 313-7.

31. Schrodt GR Melanosis coli: a study with the electron microscope. Dis Colon Rectum 1963; 6: 277-83.
32. Regitnig P, Denk H. Lack of Pseudomelanosis coli in colonic adenomas suggests different pathways of apoptotic bodies in normal and neoplastic colonic mucosa. Virchows Arch 2000; 436: 588-94.

33. Walker NI, Bennett RE, Axelsen RA. Melanosis coli. A consequence of anthraquinone-induced apoptosis of colonic epithelial cells. Am J Pathol 1988; 131: 465-76.

34. Walker NI, Smith MM, Smithers BM. Ultrastructure of human melanosis coli with reference to its pathogenesis. Pathology 1993; 25: 120-3.

35. Bosman FT, Carneiro F, Hruban RH, et al. WHO classification of tumours of the digestive system. $4^{\text {th }}$ ed. IARC Press, Lyon France 2010.

36. Miller T, Orzeszyna S. Elementy statystyki medycznej. Podręcznik dla studentów medycyny. PZWL, Warsaw 2008.

37. Oktaba W. Elementy statystyki matematycznej: metodyka doświadczalnictwa. PWN, Warsaw 1974.

38. Bockus HL, Williard JH, Bank J. Melanosis coli. The etiologic significance of the anthracene laxatives: a report of forty one cases. JAMA 1933; 101: 1-6.

39. Nascimbeni R, Donato F, Ghirardi M, et al. Constipation, anthranoid laxatives, melanosis coli, and colon cancer: a risk assessment using aberrant crypt foci. Cancer Epidemiol Biomarkers Prev 2002; 11: 753-7.

40. Price BA, Collins RE, Farley MD. Melanosis coli in a child of four years. Postgrad Med J 1980; 56: 854-6.

41. Henschen F, Bergstrand $H$. Studien über die Melanose der Darmschleimhaut. Ziegler Beitr Path Anat 1913; 56: 103-54.

42. Coyne JD. Melanosis coli can involve adenomatous polyps. Histopathology 2014; 64: 311-2.

43. Coyne JD. Melanosis coli in hyperplastic polyps and adenomas. Int J Surg Pathol 2013; 21: 261-3.

44. Byers RJ, Marsh P, Parkinson D, et al. Melanosis coli is associated with an increase in colonic epithelial apoptosis and not with laxative use. Histopathology 1997; 30: 160-4.

Received: 15.03 .2015

Accepted: 24.12 .2015 